\title{
Cost of the Scottish diet is related to energy density: analysis from the Expenditure and Food Survey
}

\author{
W. L. Wrieden ${ }^{1}$, K. L. Barton ${ }^{2}$, J. Armstrong ${ }^{3}$ and A. Sherriff ${ }^{4}$ \\ ${ }^{1}$ School of Pharmacy and Life Sciences, Robert Gordon University, Aberdeen, AB25 1HG, UK, ${ }^{2}$ Centre for Public Health \\ Nutrition Research, University of Dundee, Dundee DDI 9SY, UK, ${ }^{3}$ School of Life Sciences, Glasgow Caledonian University, \\ Glasgow G4 OBA, UK and ${ }^{4}$ University of Glasgow Dental School, Glasgow G2 3JZ, UK
}

Most dietary recommendations focus on reducing the consumption of high energy dense foods, the emphasis being on encouraging diets that contain a higher proportion of starchy carbohydrates, fish, fruit and vegetables. Several studies have investigated the cost of the diet with regards to energy density $(\mathrm{ED})^{(1-3)}$ with each finding an inverse relationship between ED and energy cost (EC), that is the higher the ED the lower the EC of the diet. These studies have used individual diet records ${ }^{(1,3)}$ or compared the cost of foods of differing energy densities $^{(2)}$. The aim of this work was to use household food purchase data to investigate the relationship between ED and EC by estimating the expenditure on food per $8368 \mathrm{~kJ}(8368 \mathrm{~kJ})$ a figure equivalent to the average energy needs of an adult.

Data for Scotland from the UK Expenditure and Food Survey (EFS) (now the Living Costs and Food module of the Integrated Household Survey) was pooled from 2001 to 2008 and analysed to estimate the average ED (for food and milk) and EC (for food and nonalcoholic drinks) per $8368 \mathrm{~kJ}$, of the Scottish diet. In addition, data were examined for differences by quintile of ED, and whether households met the dietary targets for fat and fruit \& vegetables.

The methodology and rationale for the calculation of ED from the EFS is described elsewhere ${ }^{(4)}$. Average EC, as eaten, for each household was calculated for household and eating out purchases combined by dividing the expenditure per person per day by the estimated energy intake $(\mathrm{kJ})$ per person per day and multiplying by $8368 \mathrm{~kJ}$. Data were analysed using general linear models within the complex samples module of SPSS (SPSS Inc., Chicago, IL, USA) weighting to the Scottish population and taking account of sampling methods. No adjustment was made to the EC to account for year of purchase therefore figures given should not be compared with current prices. Results are presented as population means (i.e. includes consumers and non-consumers), with $95 \%$ CI.

\begin{tabular}{|c|c|c|c|c|c|c|c|c|}
\hline & & \multicolumn{5}{|c|}{ Quintile of energy density } & \multirow[b]{2}{*}{$\begin{array}{l}P \text {-value for } \\
\text { linear trend }\end{array}$} & \multirow[b]{2}{*}{$\begin{array}{c}\text { Average } \\
(n \text { 4477) } \\
\text { (wt } n \text { 39910) }\end{array}$} \\
\hline & & $\begin{array}{c}1^{*} \\
(n 893) \\
(\text { wt } n 6593)\end{array}$ & $\begin{array}{c}2 \\
(n 896) \\
(\text { wt } n 8013)\end{array}$ & $\begin{array}{c}3 \\
(n 897) \\
(\text { wt } n 8224)\end{array}$ & $\begin{array}{c}4 \\
(n \text { 896) } \\
(\text { wt } n \text { 8817) }\end{array}$ & $\begin{array}{c}5^{*} \\
(n 895) \\
(\text { wt } n 8263)\end{array}$ & & \\
\hline $\begin{array}{l}\text { Energy density } \\
(\mathrm{kJ} / 100 \mathrm{~g})\end{array}$ & Mean & 518 & 633 & 703 & 785 & 969 & & 723 \\
\hline & $95 \% \mathrm{CI}$ & 514,522 & 631,634 & 702,705 & 783,787 & 959,979 & & 717,729 \\
\hline Cost $(£ / 8368 \mathrm{~kJ})$ & $\begin{array}{l}\text { Mean } \\
95 \% \text { CI }\end{array}$ & $\begin{array}{l}4.97 \\
4.69,5.25\end{array}$ & $\begin{array}{l}4.84 \\
4.62,5.06\end{array}$ & $\begin{array}{l}4.40 \\
4.24,4.57\end{array}$ & $\begin{array}{l}4.28 \\
4.14,4.43\end{array}$ & $\begin{array}{l}3.76 \\
3.60,3.92\end{array}$ & $<0.001$ & $\begin{array}{l}4.42 \\
4.31,4.54\end{array}$ \\
\hline
\end{tabular}

*Energy density quintiles: $1=$ Least Dense; $5=$ Most Dense; $n$ refers to the number of households and weighted (wt) $n$ refers to the weighted number of people in the sample.

Analysis by quintiles of ED found a significant inverse relationship between ED and EC. The mean EC of households achieving the Scottish Dietary Targets for fat $(\leq 35 \%$ food energy) and fruit \& vegetables ( $\geq 400 \mathrm{~g}$ per day) was $£ 4.89 / 8368 \mathrm{~kJ}(95 \% \mathrm{CI} 4.66,5.12)$ compared with $£ 4.40 / 8368 \mathrm{~kJ}(95 \% \mathrm{CI} 4.28,4.51)$ for non achieving households. The mean ED of the diets were $574 \mathrm{~kJ} / 100 \mathrm{~g}(95 \% \mathrm{CI}$ $564,584)$ compared with $734 \mathrm{~kJ} / 100 \mathrm{~g}(95 \%$ CI 728,740$)$, respectively.

Food purchase data from the EFS have successfully provided a means of investigating the relationship between ED and EC of the Scottish diet. The results show that there is an inverse relationship between ED and EC. Further work needs to be done to establish how ED can be reduced without cost implications.

Funded by the Scottish Government and Food Standards Agency Scotland (Project no. S14035). Data provided by DEFRA, Scottish Neighborhood Statistics, ONS and the UK Data Archive.

1. Maillot M, Darmon N, Vieux F et al. (2007) Am J Clin Nutr 86, 690-696.

2. Monsivais P \& Drewnowski A (2007) J Am Diet Assoc 107, 2071-2076.

3. Waterlander WE, de Haas WE, van Amstel I et al. (2010) Public Health Nutr 13, 1599-1608.

4. Barton KL, Wrieden WL, Armstrong J et al. Proc Nutr Soc (In the Press). 